\title{
Research on Emotional Management of College Students from the Perspective of Mental Health
}

\author{
Lili Fang \\ Jilin Justice Officer Academy, Changchun, Jilin, 130062 \\ Email: lifang1974324@163.com
}

Keywords: Mental Health, College Students, Emotional Management

\begin{abstract}
Psychological health is an important determinant of the individual development of college students, and emotional management is particularly important in the mental health of college students. From the perspective of college students' mental health, this paper first analyzes the importance line of emotion management, then expounds the influencing factors of emotional management, and finally, puts forward effective ways of college students' emotional management, so as to provide some reference suggestions for college students' emotional management.
\end{abstract}

\section{Introduction}

"Fudan poisoning" and "Majiajue case" happened to the community of university students' mental health and emotion management is more and more worried. The mental health and emotional management of college students are an important part of social harmony, which should pay attention to the emotional management of college students in the training of university talents.

\section{The Importance of Emotional Management to the Individual Development of College Students}

College Students' mental health is the premise of a harmonious campus. To do well in college students' emotional management is an important guarantee for a harmonious campus, and an integral part of College Students' individual development. To do a good job of College Students' emotional management can effectively improve the students' cognitive level, make their behavior more civilized and reduce the occurrence of bad events [1]. Emotional management is closely related to mental health, and emotional control is an important manifestation of mental health. The proper emotional management can promote the healthy development of the body and mind; the emotional management may not affect the work and the quality of life, and the physical and mental health of the individual is hindered. Emotion is an important determinant of communication between people and people. Positive emotional state can make communication more harmonious, and people are more friendly to people [2]. To do a good job of College Students' emotional management can make teachers and students, students and students get along more harmoniously, which is the prerequisite for the construction of a harmonious campus culture.

\section{Influence Factors of College Students' Emotion}

Emotional management is the product of modern civilization and a concentrated expression of new management ideas and methods. Emotion management requires individuals to understand their emotional characteristics, adopt a scientific and reasonable emotional regulation mechanism, and actively eliminate negative effects brought by negative emotions, so as to make themselves more positive [3]. The emotion of college students is influenced by many factors. To do a good job of College Students' emotional management, the influence factors should be analyzed.

\subsection{School aspects}

Colleges and universities are important bases for talent training, which makes many schools 
neglect the importance of emotional management to the training of talents in the construction of educational system. The neglect of the school leads to the serious derailment of the moral education and the mental health education of the college students, and the serious lack of the students' emotional management. Some universities have realized the importance of emotional management for talent training and arranged some young teachers who are good at common [4]. Teachers in class follow the traditional "lecture type" education model in the classroom, and lack communication with students, which leads to frequent emotional problems in communication between teachers and students.

\subsection{Family aspects}

Family factors are important determinants of individual behavior, and college students' emotion is more influenced by family factors. Many college students say that "bad temper" is a habit of catharsis at home or at home, which also proves the influence of family factors on College Students' mood [5]. The degree of parents' culture, personal accomplishment and family harmony are all the family factors that affect the emotion of college students.

\subsection{Professional learning}

Students in Colleges and universities are unavoidable to be adjusted. Students are not interested in being transferred to the major, and the learning process is not active and the learning efficiency is low. Professional learning is completely in a passive state, which can easily lead to weariness of learning.

\subsection{The ability to recognize emotion}

"Emotional IQ" is a manifestation of the ability to identify emotions in the mental health of a university, and is the ability to discover problems in time when some kind of emotion appears. High emotional intelligence should not only have a certain level of cognition of their own emotions, but also have a considerable cognitive level of others' emotions. In other words, we can identify others' emotions from other's mood and body language [6]. Students with poor emotional recognition ability are self - centered in communication and have poor communication and harmony.

\section{Effective Ways of College Students' Emotional Management}

\subsection{Optimize the educational environment}

The school should do everything possible to create a good campus environment for the students, which is the primary task of attaching importance to the emotional management of college students. Schools should organize all kinds of teachers to participate in community activities and art salons, so that campus culture can be more abundant. Students can be happier in this campus environment and keep students in good mood. Although many colleges and universities have a psychological consultation room, the consulting room is usually accompanied by a part-time teacher, which makes the student counseling work not professional enough. Many students wrongly believe that going to the counseling room is "brain problem". This requires that schools should optimize school psychological counseling stations and employ professional counselors to engage in psychological counseling for students, so that psychological counseling is more professional, and students are more willing to enter psychological counseling room for psychological and emotional counseling [7-8]. A teacher in charge of a class plays an important role in the group of college students. Schools should employ young teachers with good psychological quality, proper emotional control and good communication as head teachers. The emotional management ability of head teachers is closely related to the harmonious atmosphere of class. Doing well in emotional management of college students requires that a teacher in charge of a class should take emotion as the main line and actively guide students to control their emotions.

The two level college should also actively encourage the class to carry out activities and strive for a harmonious class culture, which plays an important role in the emotional management of college students. A teacher suggested that the teacher behavior has an important role in the 
cultivation of students. This also requires attention to the teacher's emotional management and adjustment, so that the teacher can maintain positive and good mood, and play an example role in the student group.

\subsection{Promote the harmony of the family environment}

College students are not fully mature, and their parents' daily behavior is also the guidance of College Students' behavior. Through many studies, it is known that the high quality of the parents, the proper emotional control, the children's emotional management ability and Emotional IQ are high. But children who grow up in tempers, self-center and violent family environment are poor in general mood management, which is called "temper heredity". In order to make the college students better manage their emotions from the family, it is necessary to infiltrate the mental health and emotional management education from the school into the students' families. Let students and parents at the same time receive education, and let parents in the meantime with children at the same time accept mental health and emotional management education, timely find children's emotional problems, and make family get more harmonious [9]. Parents should communicate with children in depth, explore the inner world of children, making children feel warm and love, keep their children active and sunny, and have more harmonious family life and study life.

\subsection{Learn to manage emotions}

The key to the emotional management of college students is the students themselves. College students should use appropriate emotional expression to express their emotions, and they should also respond to emotional responses. For their own bad mood, we should adopt a reasonable way of catharsis to minimize the adverse effects on others because of their own emotional catharsis. The emotional response is reflected in the "moderate" two words, the intensity, the way and the time should be adapted to the specific situation.

\subsubsection{Be aware of emotions in time}

People have social attributes, and people inevitably produce emotions in society. If they can suppress emotion, it will affect the health of the body and mind. The perception of self-emotion is the first and most important step in emotional management, and it is the embodiment of individual self-cognition. It is obviously useless to vent blindly when we are in the mood. At this point, it is necessary to analyze the cause of the emotion and ask yourself if you are worth the anger or when you are angry, can you solve the problem [10]. That is to say, we need to have rational thinking to deal with problems, identify the key to solve problems, avoid losing emotions and maintain a steady, positive and optimistic mood.

\subsubsection{Express emotion reasonably}

The rational expression of emotion is the expression of "high EQ", and it is also an important way of harmonious interpersonal communication. Most college students are "babe" at home. They are difficult to control emotional expression. They often have different emotions in adapting to different ways and contents of communication in school nuclear and social interactions. Of course, emotion also affects the application of communication and the expression of communication content. Positive and healthy emotions can make expression of inner feelings, enable others to have a deeper understanding of you, enhance feelings and close ties between two parties, and negative emotions often make communication between the two sides more intense.

\subsubsection{Adjust the mood in a reasonable way}

College students are also unavoidable to meet the high pressure situation, at this time we can adopt a reasonable way to carry out emotional catharsis, for example, to open the open place to shout and vent. It is an essential part of College Students' emotional management to adjust their own emotions in a reasonable way. It is an effective way to maintain a healthy state of mind for a long time. The emotional adjustment is an important way of emotional adjustment. 


\section{Conclusions}

The pressure and life pressure of our country are constantly increasing. College students should participate in social work sooner or later. How to manage emotional management in a high pressure state is what college students should master. Schools, teachers, parents and college students themselves should take corresponding measures to manage emotions, make people get along with people more harmoniously, and then promote social harmony.

\section{References}

[1] Wang X, Wang J, Zhang L. Analysis on the Psychological Adjustment of College Students Based on the Principle of Self-Management[M]// Informatics and Management Science I. Springer London, 2013:537-543.

[2] Jia J, University H G. A Study on the Ideological and Political Education of College Students from the Perspective of Capacity Core Management[J]. Journal of Hebei Geo University, 2017.

[3] Sun Y, Yang Y Y, Feng C X, et al. The Research on Negative Perfectionism Personality of Engineering Students from the Perspective of Game Theory[M]// The 19th International Conference on Industrial Engineering and Engineering Management. Springer Berlin Heidelberg, 2013:289-297.

[4] Song X, Fu L. The Study of College Students' Beliefs in China[J]. Pastoral Psychology, 2012, 61(5-6):923-940.

[5] Xiong M N, Li-Qiong M O. Research on Thinking and Governance of Sports and Health Management for College Students from the Perspective of Life Philosophy[J]. 2017(icesd).

[6] Michalec B, Keyes C L. A multidimensional perspective of the mental health of preclinical medical students[J]. Psychology Health \& Medicine, 2013, 18(1):89-97.

[7] Wang Q, Shang L, Fang Y. [Research on the mental health of the parents of cleft lip and palate patients and social impact factor from the perspective of social network]. [J]. Hua xi kou qiang yi xue za zhi = Huaxi kouqiang yixue zazhi = West China journal of stomatology, 2012, 30(4):374.

[8] Mclean N, Marshall L A. A front line police perspective of mental health issues and services. [J]. Criminal Behaviour \& Mental Health Cbmh, 2010, 20(1):62.

[9] M. ROBERTS rmn diphe ba (hons) pgce pgcrm ma phd. Emotional intelligence, empathy and the educative power of poetry: a Deleuzo-Guattarian perspective[J]. Journal of Psychiatric \& Mental Health Nursing, 2010, 17(3):236-241.

[10] Sharabinov M H A. Teaching the teachers: emotional intelligence training for teachers[J]. Teaching Education, 2014, 25(4):375-390. 